\title{
Clozapine-induced fatal fulminant hepatic failure: A case report
}

\author{
Albert Chang MD, Darin S Krygier MD, Nazira Chatur MD, Eric M Yoshida MD
}

\begin{abstract}
A Chang, DS Krygier, N Chatur, EM Yoshida. Clozapineinduced fatal fulminant hepatic failure: A case report. Can J Gastroenterol 2009;23(5):376-378.

Fulminant hepatic failure (FHF) refers to the rapid development of severe acute liver injury with impaired synthetic function and encephalopathy in a person who previously had a normal liver or had wellcompensated liver disease. The potential causes of FHF are numerous, but viral or toxin-induced hepatitis are the most common. Clozapineinduced hepatotoxicity has rarely been reported in the literature, occurs via an unknown mechanism and results in liver biochemical abnormalities that are usually of no clinical significance. In approximately $30 \%$ to $50 \%$ of patients treated with clozapine, there is an asymptomatic rise in serum aminotransaminase levels; however, there are no current guidelines for routine monitoring of liver function tests and liver enzymes during its use. Fatal fulminant hepatitis has only been reported in three patients receiving clozapine. A case of fatal FHF that occurred in a schizophrenic woman who began clozapine therapy shortly before her illness developed is described.
\end{abstract}

Key Words: Clozapine; Fulminant hepatic failure; Schizophrenia

$\mathrm{M}$ any medications are associated with hepatic toxicity. The severity of drug-induced hepatic injury can range from transient asymptomatic liver enzyme elevation (transaminitis) to fulminant hepatic failure (FHF). The exact incidence of FHF remains uncertain, but studies suggest that the leading causes in North America are drug overdose and idiosyncratic drug reactions (1). Clozapine (Clozaril, Sandoz Pharmaceuticals, Germany) is an atypical antipsychotic used in the treatment of schizophrenia. It was introduced in the early 1970s, and subsequent clinical trials demonstrating fatal agranulocytosis resulted in a reduction in the frequency of its use. Clozapine has also been associated with numerous gastrointestinal side effects including constipation, bowel ischemia and hepatitis (2-4). There is little reported in the literature regarding acute clozapine-induced FHF apart from one case report (2). The present article describes a case of clozapine-induced fatal FHF.

\section{CASE PRESENTATION}

A woman in her fifth decade was examined by the gastroenterology service because of jaundice. She was admitted to hospital under the care of the psychiatry service due to increased delusions and a decreased ability to function independently. She had a history of paranoid schizophrenia with catatonic features and passive-aggressive behaviour. She also had type 2 diabetes and a gynecological malignancy that had been treated surgically one year earlier. Her medications before hospitalization included levothyroxine, risperidone and olanzapine, but she

\author{
Insuffisance hépatique fulminante fatale \\ induite par la clozapine : Rapport de cas
}

Le terme insuffisance hépatique fulminante (IHF) fait référence à l'installation rapide d'une atteinte hépatique aiguë et grave, accompagnée de perturbations des fonctions de synthèse du foie et d'encéphalopathie chez une personne dont la fonction hépatique était auparavant normale ou qui souffrait d'une maladie hépatique compensée. Les causes potentielles de l'IHF sont nombreuses, mais les plus courantes sont l'hépatite virale ou l'hépatite induite par une toxine. L'hépatotoxicité induite par la clozapine a fait l'objet de rapports peu nombreux dans la littérature; son mécanisme est encore mal élucidé et elle entraîne des anomalies biochimiques hépatiques habituellement sans importance clinique. En effet, chez environ $30 \%$ à $50 \%$ des patients traités par clozapine, on note une élévation asymptomatique des taux d'aminotransaminases sériques. Toutefois, il n'existe aucune directive actuellement pour la vérification systématique des analyses de fonction hépatique et des taux d'enzymes hépatiques durant l'utilisation de ce médicament. L'hépatite fulminante fatale n'a été signalée que chez trois patients traités par clozapine. On décrit ici un cas d'IHF fatale survenue chez une femme schizophrène qui avait commencé un traitement par clozapine peu de temps avant l'apparition de la maladie. had a longstanding history of poor compliance. She denied having a history of alcohol use, smoking or intravenous drug use. She had no known history of liver disease.

Her regular antipsychotic medications were not continued after hospital admission and she was started on clozapine with the dose titrated from $150 \mathrm{mg}$ daily to $300 \mathrm{mg}$ daily. Baseline laboratory results collected on admission included a normal platelet count, normal liver enzymes and liver function tests. Her preadmission laboratory investigations were also normal, including an alanine aminotransferase (ALT) level of $60 \mathrm{U} / \mathrm{L}$ and an aspartate aminotransferase (AST) level of $26 \mathrm{U} / \mathrm{L}$ (ALT normal at less than $65 \mathrm{U} / \mathrm{L}$; AST normal at less than $38 \mathrm{U} / \mathrm{L})$. Six weeks after initiation of clozapine, the patient complained of mild nausea and right upper quadrant pain, and was noted to have developed jaundice. She subsequently developed nausea, emesis and anorexia. Her physical examination revealed severe drowsiness with easy rousability and no asterixis. She had a mildly distended soft abdomen with tenderness in the right upper quadrant. There were no stigmata of chronic liver disease. Laboratory results obtained 8.5 weeks after clozapine initiation revealed a white blood cell count of of $7.5 \times 10^{9} / \mathrm{L}$ without eosinophilia, hemoglobin $122 \mathrm{~g} / \mathrm{L}$, platelet count of $198 \times 10^{9} / \mathrm{L}$, AST $890 \mathrm{U} / \mathrm{L}$, ALT $1668 \mathrm{U} / \mathrm{L}$, direct bilirubin $212 \mu \mathrm{mol} / \mathrm{L}$, total bilirubin $321 \mu \mathrm{mol} / \mathrm{L}$, alkaline phosphatase $273 \mathrm{U} / \mathrm{L}$, albumin $27 \mathrm{~g} / \mathrm{L}$, international normalized ratio 2.9 and creatinine $54 \mathrm{mmol} / \mathrm{L}$. Her clozapine was immediately discontinued. An abdominal ultrasound with Doppler assessment of 


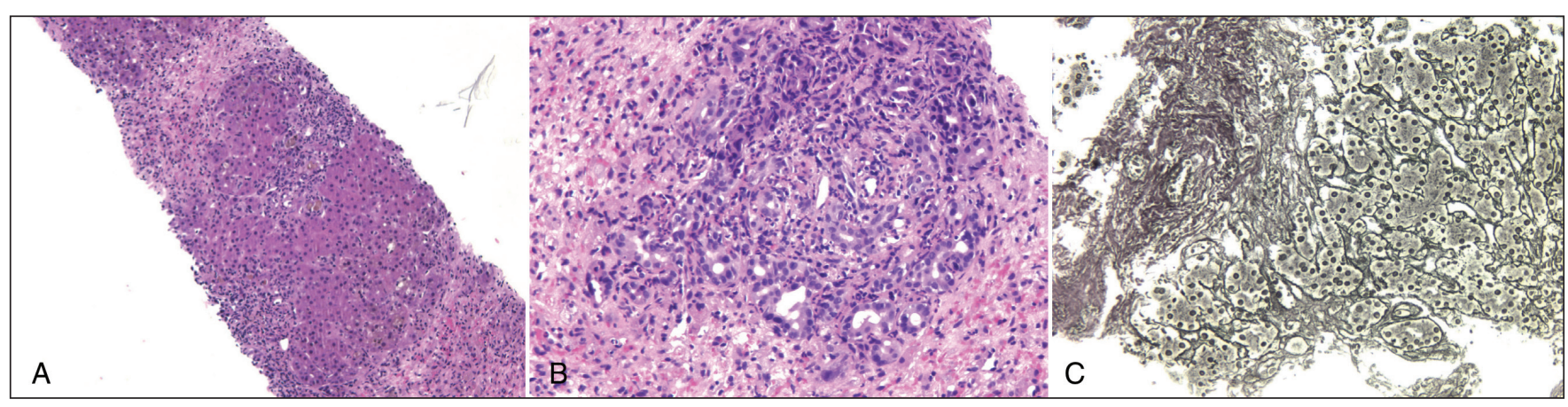

Figure 1) A Liver biopsy stained with hematoxylin and eosin demonstrating hepatocyte necrosis with some periportal sparing, mild chronic inflammation, marked bile stasis and relative preservation of portal to central vein relationships; $\mathbf{B}$ High-powered view of a portal triad; $\mathbf{C}$ Reticulin stain demonstrating immature fibrosis and collapse of the reticulin framework

hepatic vessel flow revealed a small collapsed liver with no focal lesions.

Laboratory results for infectious (viral) serology, including hepatitis A, B and C, Epstein-Barr virus and cytomegalovirus, were negative. An autoimmune analysis was negative for antimitochondrial antibody, antinuclear antibody, antismooth muscle antibody and tissue transglutaminase antibody. Her urine toxicology screen, acetaminophen and alcohol levels were negative. Her serum ceruloplasmin and serum iron studies showed no evidence of copper or iron overload. Her serum alpha 1 antitrypsin level, serum immunoglobulin (Ig) G, IgA and IgM levels were normal. A full assessment was performed by the liver transplant service and she was deemed not to be a suitable transplant candidate. This decision was based on the patient's history of poor compliance with her psychiatric medications, poorly controlled psychiatric disease, limited social support and recent gynecological malignancy, factors that significantly compromised the likelihood of a reasonable posttransplant outcome.

She subsequently developed periods of hypothermia, marked ascites and peripheral edema. Paracentesis revealed an ascitic fluid white blood cell count of $600 \times 10^{9} / \mathrm{L}$ with $26 \%$ neutrophils. Her blood and urine were taken several times; the resulting cultures were negative. Her platelet count progressively decreased and her renal function began to fall. She received intravenous albumin infusions daily for five days. She then developed mild encephalopathy, which was treated with lactulose.

Eleven-and-a-half weeks after starting clozapine, and three weeks after its discontinuation, she underwent a transjugular liver biopsy. Because she had persistent coagulopathy with thrombocytopenia, she received four units of fresh frozen plasma before the procedure. Middle hepatic wedge pressure was $44 \mathrm{mmHg}$ and the central venous pressure was $10 \mathrm{mmHg}$. A liver needle core biopsy revealed massive zonal necrosis with approximately two-thirds of the tissue being necrotic (Figure 1). Periportal sparing, collapse of the reticulin framework, mild chronic inflammation, marked bile stasis and immature fibrosis was also demonstrated (Figure 1). Steatosis was not seen and there was no demonstrable excess of iron or copper.

The patient subsequently developed acute respiratory distress syndrome and multiorgan failure. Despite admission to the intensive care unit, mechanical ventilation and intense critical care support, she died 12.5 weeks after clozapine was started.

\section{DISCUSSION}

Clozapine-induced FHF is an uncommon, but recognized, complication of clozapine therapy (2). Well-documented side effects limiting clozapine use include agranulocytosis, seizures, orthostatic hypotension, hypertension and drowsiness. From a gastrointestinal perspective, documented side effects include abnormal liver function tests, constipation, bowel ischemia and ascites $(3,4)$. There have been five cases of clozapine-associated hepatitis reported in the literature $(4-7)$ and, to the best of our knowledge, the present case is only the second documented report of a patient with FHF leading to death as a result of treatment with clozapine (2).

The mechanism of clozapine-induced liver injury is unclear. The drug is metabolized in the liver via the cytochrome P450 pathway. It has been suggested that patients who experience drug-induced hepatitis with any medication may be vulnerable to clozapine-induced acute hepatitis (8). Icteric hepatitis with accompanying nausea has been documented four times and zone 3 necrosis was demonstrated on liver biopsy in one case $(7,9)$. Fulminant hepatitis with encephalopathy and coagulopathy has rarely been reported (2).

It has been suggested that regular monitoring of liver enzymes is not necessary, given that the incidence and risk of serious clozapine-induced hepatotoxicity is low. Approximately $40 \%$ of subjects receiving clozapine have ALT or alkaline phosphatase levels twice the upper limit of normal $(10,11)$. Recovery from clozapine-induced hepatitis appears to occur in the majority of patients when the medication is stopped (4). In retrospect, documentation of abnormalities in liver enzymes along with a worsening clinical picture and earlier cessation of clozapine may have prevented the present patient from developing fatal FHF. Therefore, our experience should be of interest to clinicians prescribing clozapine.

\section{IMPLICATIONS FOR CLINICAL CARE}

Asymptomatic transaminitis is commonly associated with clozapine therapy. However, caution is advised for patients with elevated liver enzymes who are receiving clozapine because the transaminitis may be the earliest manifestation in the development of FHF. Unfortunately, it is not possible to reliably predict which patients will progress to hepatic failure. Nevertheless, it may be prudent to diligently follow biochemical liver tests in patients receiving clozapine to monitor for early evidence of the development of FHF and possibly death. 


\section{Chang et al}

\section{REFERENCES}

1. Ostapowicz G, Fontana RJ, Schiodt FV, et al. Results of a prospective study of acute liver failure at 17 tertiary care centers in the United States. Ann Intern Med 2002;137:947-54.

2. Macfarlane B, Davies S, Mannan K, et al. Fatal acute fulminant liver failure due to clozapine: A case report and review of clozapineinduced hepatotoxicity. Gastroenterology 1997;112:1707-9.

3. Pelizza L, De Luca P, La Pesa M, et al. Clozapine-induced intestinal occlusion: A serious side effect. Acta Biomed 2007;78:144-8.

4. Luo D, McColl P, Walmsley R. Acute onset of ascites with clozapineinduced hepatitis. Internal Med J 2007;37:204-5.

5. Worrall R, Wilson A, Cullen M. Dystonia and drug-induced hepatitis in a patient treated with clozapine. Am J Psychiatry 1995;152:647-8. 6. Wirshing WC, Ames D, Bisheff S, et al. Hepatic encephalopathy associated with combined clozapine and divalproex sodium treatment. J Clin Psychopharmacol 1997;17:120-1.

7. Thatcher GW, Cates M, Bair B. Clozapine-induced toxic hepatitis. Am J Psychiatry 1995;152:296-7.

8. Jang SJ, Yi HT, Paek HJ, et al. Clozapine-induced acute hepatitis. J Korean Neuropsychiatr Assoc 1999;38:227-33.

9. Hovens JE, Vogtlander LM, Verhoeve HA, et al. Liver cell necrosis caused by clozapine. Ned Tijdschr Genneeskol 1994;138:365-8.

10. Hummer M, Jurz M, Jurzthaler I, et al. Hepatotoxicity of clozapine. J Clin Psychpharmacol 1997;17:314-7.

11. Gaertner I, Altendorf K, Batra A, et al. Relevance of liver enzyme elevations with four different neuroleptics: A retrospective review of 7263 treatment courses. J Clin Psychpharmacol 2001;21:215-22. 


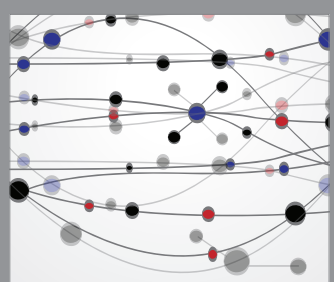

The Scientific World Journal
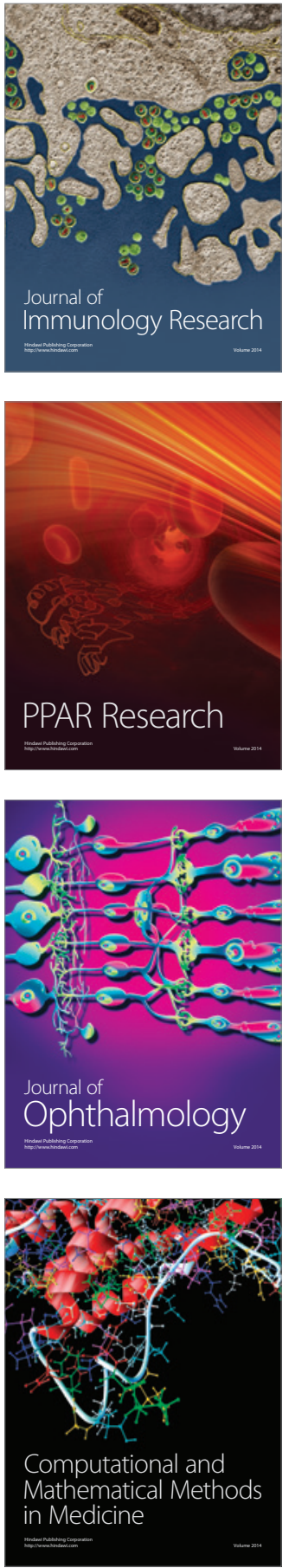

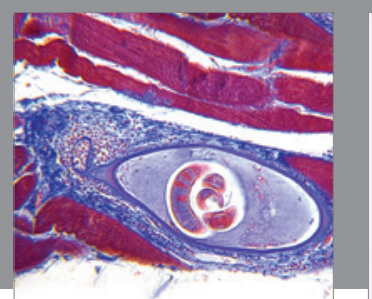

Gastroenterology Research and Practice

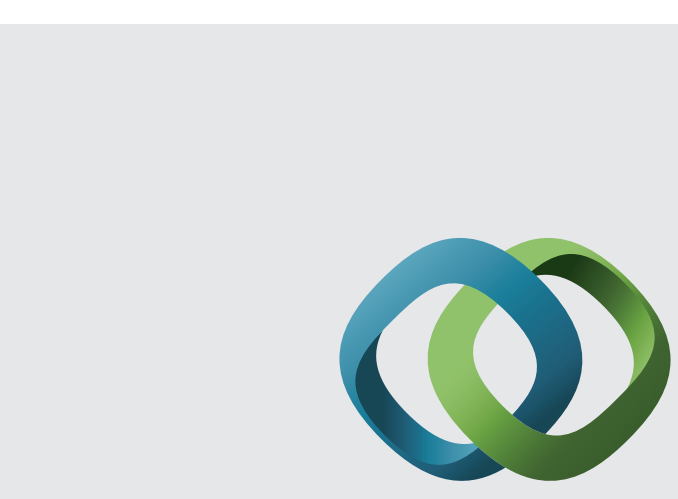

\section{Hindawi}

Submit your manuscripts at

http://www.hindawi.com
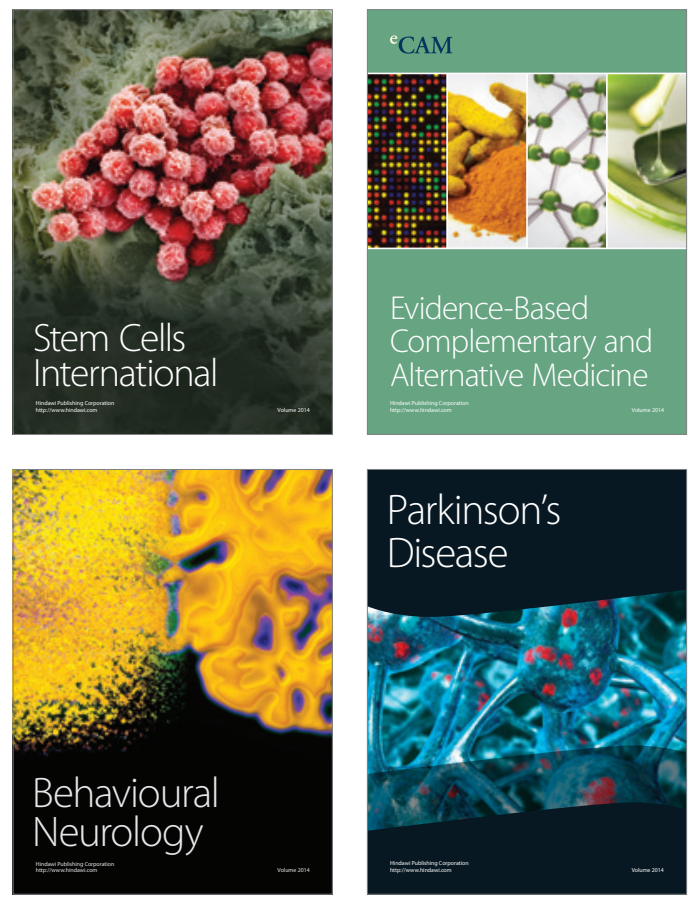
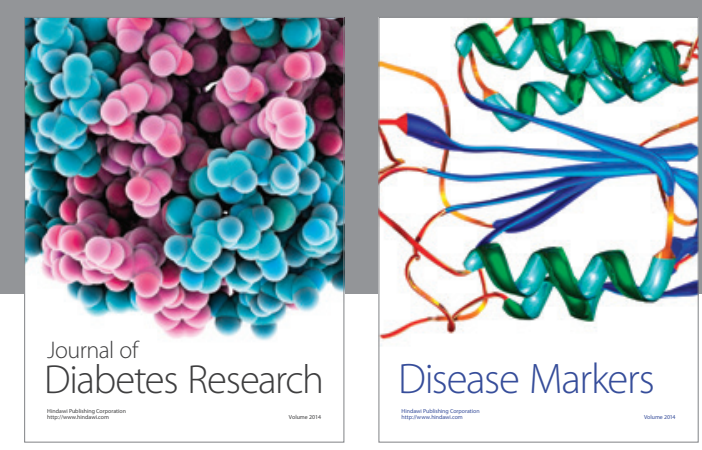

Disease Markers
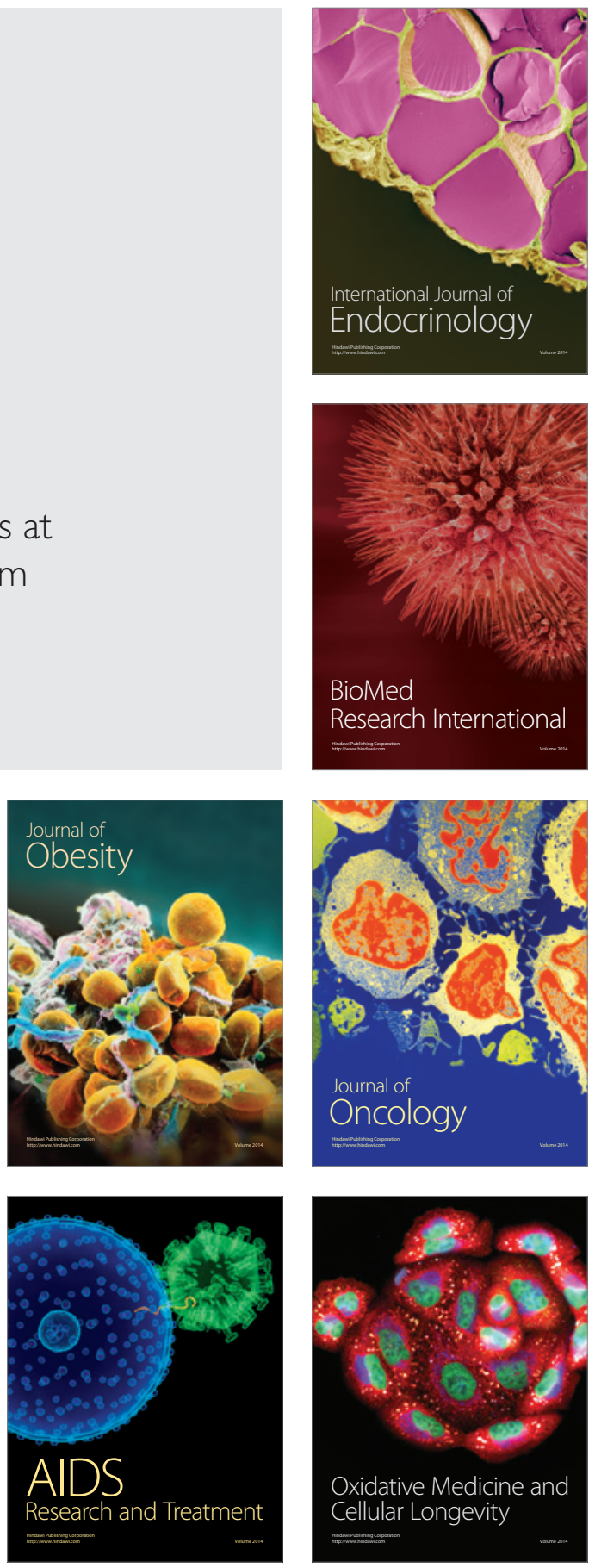